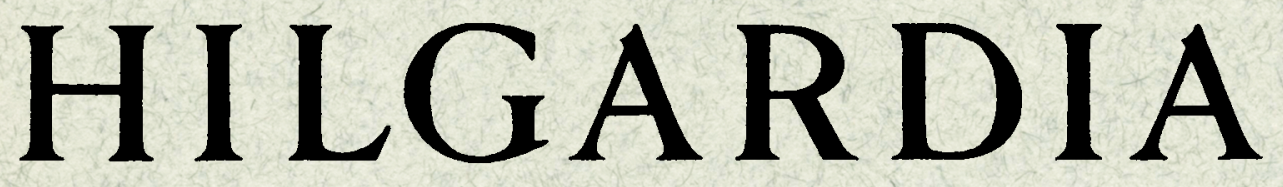

A Journal of Agricultural Science Published by the California Agricultural Experiment Station

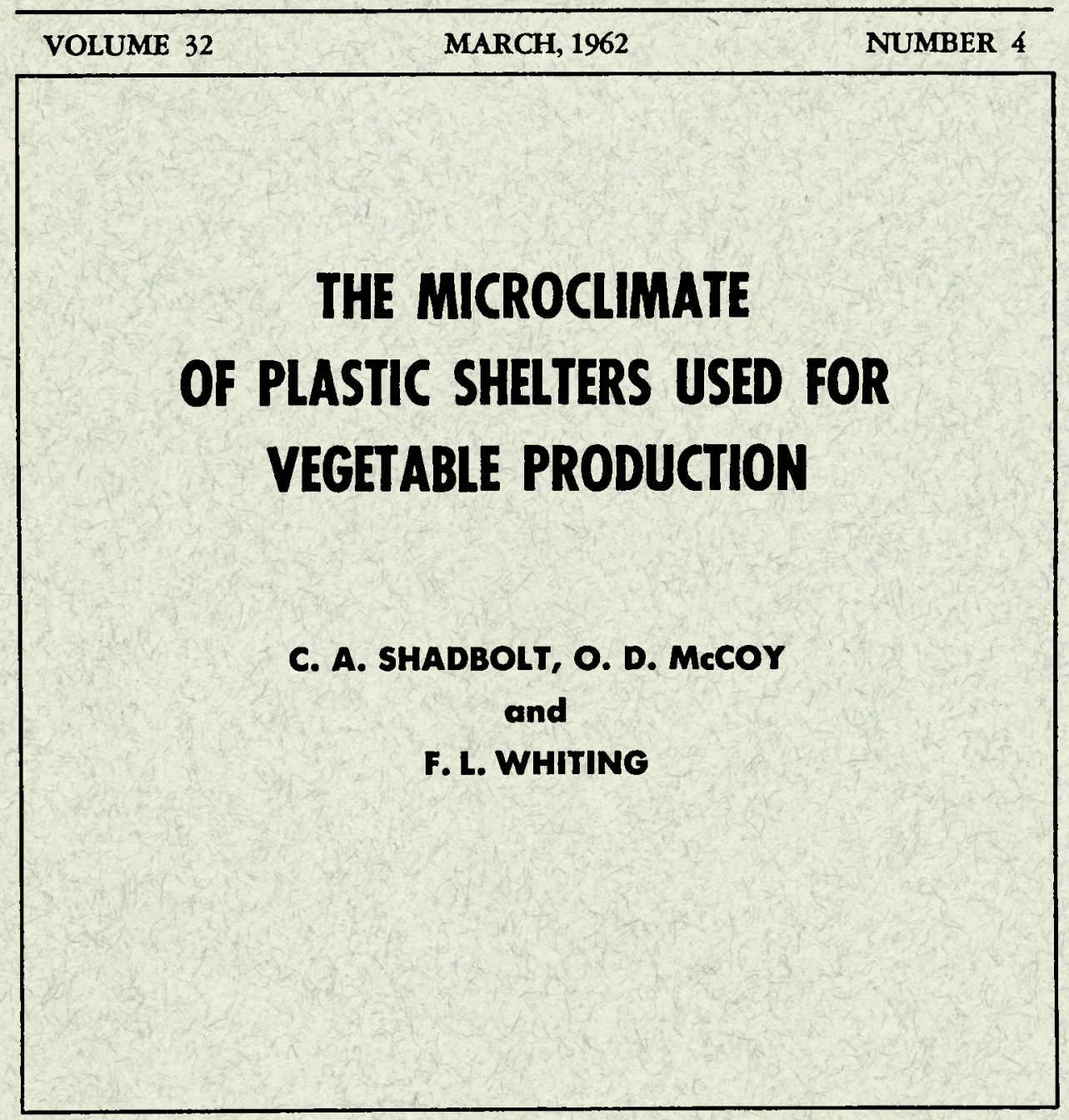

UNIVERSITY OF CALIFORNIA - BERKELEY, CALIFORNIA 


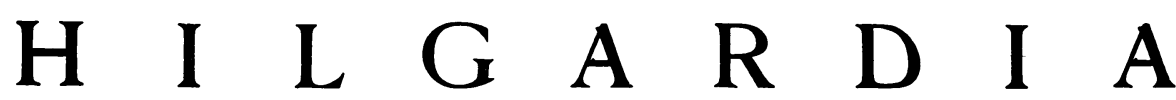

A Journal of Agricultural Science Published by

the California Agricultural Experiment Station

\begin{tabular}{lll}
\hline VoL. 32 & MARCH, 1962 & No. 4 \\
\hline
\end{tabular}

\section{THE MICROCLIMATE OF PLASTIC SHELTERS USED FOR VEGETABLE PRODUCTION ${ }^{1}$}

\author{
C. A. SHADBOLT, ${ }^{2}$ O. D. MCCOY, ${ }^{3}$ and F. L. WHITING ${ }^{4}$
}

\section{INTRODUCTION}

IN MANY AREAS of California, warm-season crops such as cantaloupes, cucumbers, tomatoes, and peppers are planted during winter or early spring and are artificially provided with an environment suitable for growth during a period of adverse temperature conditions. This is accomplished by means of paper or plastic structures placed over the growing plants which provide, in effect, a miniature greenhouse. In the past, paper was used almost exclusively as hotcap material. Recently, however, plastic has been used as continuous row covers or tunnels and has been shown to be superior in many respects to the conventional paper (Shadbolt and McCoy, 1960). ${ }^{5}$ As these covers often remain in place for as long as three months, temperature, humidity, and other environmental factors must be maintained in order to provide good growing conditions for the plants.

Previous studies (Shadbolt and McCoy, 1960) have indicated that the shape and method of ventilation of these continuous covers have a marked influence on the soil and air temperatures as well as on plant response. It was considered desirable to expand these studies and to determine more critically the effects of these factors on the temperature patterns throughout the enclosed air and soil. Accordingly, experiments were conducted at the University of California Imperial Valley Field Station near Holtville and at the University of California, Riverside, during the winters of 1960 and 1961.

Polyethylene mulching has also been used in many vegetable-growing areas of the country to increase earliness and yields. In contrast to raised covers, mulches involve the control of conditions primarily below the soil surface. Both clear and black films have been successfully used. Clear film has been shown to provide a greater increase in soil temperature than black film (Voth

\footnotetext{
${ }^{1}$ Paper No. 1337, University of California Citrus Research Center and Agricultural Experiment Station, Riverside. Received for publication September 1, 1961.

${ }^{2}$ Formerly Assistant Olericulturist, Department of Vegetable Crops, Riverside. Now in Kansas City, Missouri.

${ }^{3}$ Associate Specialist, Department of Vegetable Crops, Imperial Valley Field Station, El Centro.

${ }^{4}$ Laboratory Technician II, Department of Vegetable Crops, Riverside.

"See "Literature Cited" for citations, referred to in the text by author and date.
} 
and Bringhurst, 1959; Waggoner et al., 1960). It has also been shown (Honma et al., 1959; Voth and Bringhurst, 1959; Waggoner et al., 1960) that soil temperatures, at least during part of the day, are often lower under black mulch than in uncovered soil. It is a common observation that maximum soil temperatures are lower and minimums are higher under black mulch than when no cover is used. The average daily temperature under black mulch, however, is usually higher than in uncovered soil. In addition to the soil temperature advantage, mulches reduce soil evaporation, increase the utilization of nitrogen (Clarkson, 1960), and protect produce from direct contact with the soil. Black mulch also provides weed control.

\section{METHODS}

During the winter of 1960 , a study was made of the temperature patterns under plastic ${ }^{6}$ covers at the Imperial Valley Field Station. Covers were erected on the south-facing slope of large melon beds oriented in an east-west direction. The beds were sloped about fifteen degrees from the horizontal and were on seven-foot centers. The covers were centered over a point approximately twenty-seven inches from the furrow, where the plant row is normally placed. Two shapes of covers were used, both made from thirty-six inch, 1.5mil polyethylene, and both with about twenty-eight inches of film exposed above the ground. One cover had a base width of twenty-two inches and was from eight to nine inches high; the other had a base width of eleven inches and was from eleven to twelve inches high. Both perforated and unperforated films were used. Perforations consisted of holes three-sixteenths of an inch in diameter, spaced two by three inches throughout the center eighteen inches of the film. At the time that temperatures were taken, some of the covers had been lifted approximately one inch on the south or lower side to provide ventilation. Cantaloupe plants were growing under the covers but they were small and offered no shading at the time of reading.

Three thermocouples were placed one inch deep in the soil under each of the covers. One was placed at the center of the cover, and one at each of the north and south sides, two inches from the wall.

Thermocouples used for determining air temperature were shaded from the direct rays of the sun. Shields were made by splitting one-inch Lucite tubing lengthwise and painting with flat white paint. Thermocouples were inserted into a small hole drilled one-half inch from the end of the split tube, and it was placed so that the thermocouple was shaded from the south, east, and west. Five thermocouples for recording air temperature were placed under each of the covers. Three were placed one inch above the soil surface, directly above those in the soil. One was placed one inch from the film at the top of the cover, and the other in the center, midway between the top and bottom.

Gas samples were collected under perforated and unperforated covers on several dates and at several times of the day and night. Collection was made by displacement of a saturated solution of sodium chloride. Samples were analyzed for carbon dioxide by the use of an Orsac gas analyzer.

\footnotetext{
${ }^{6}$ Plastic used throughout this study was supplied by the Visking Company.
} 
Similar tests were set up at Riverside, California, in the winter of 1961. Unlike the previous year, the covers were constructed on flat ground rather than on a sloping bed. Continuous covers of four sizes were erected over wire wickets from five-foot-wide unperforated 1.5-mil polyethylene. The bases of the covers were one, two, three, and four feet wide. A four-foot width of plastic was exposed above the soil in each case, six inches on either side being anchored by soil. The plastic on the last-named cover was flat on the soil surface and will be referred to as "mulch." In addition to the mulch using clear plastic, a similar four-foot mulch was set up, using black plastic. A description of the covers with regard to soil area, height, volume, and plastic area per linear foot is shown in table 1.

Thermocouples were placed under each of the raised covers in a gridlike pattern to determine air temperatures. Because of the wide variation in

TABIE 1

DIMENSIONS OF THE PLASTIC COVERS USED IN THIS STUDY*

\begin{tabular}{c|c|c|c}
\hline \hline $\begin{array}{c}\text { Soil area } \\
\text { (base width) }\end{array}$ & Height & Volume & Plastic area \\
\hline 1 sq. ft. & 21 in. & 1.56 cu. ft. & 4 sq. ft. \\
2 sq. ft. & 17 in. & 2.35 cu. ft. & 4 sq. ft. \\
3 sq. ft. & 13 in. & 2.26 cu. ft. & 4 sq. ft. \\
4 sq. ft. & 0 in. & 0.00 cu. ft. & 4 sq. ft. \\
\hline
\end{tabular}

*Area and volume measurements are based on one linear foot of structure.

temperature found under the covers in the previous season when five thermocouples were used, thirteen to sixteen thermocouples, depending upon cover size, were placed under each cover this season. Four basic positions were used. Three thermocouples were placed one inch above the soil level, one in the center of the cover, one at each edge one inch from the wall, and one was placed one inch from the top of the cover. Others were systematically arranged throughout the cover, not more than five inches apart in a vertical or horizontal direction.

Shading was accomplished by the use of small wooden shields, cut in such a manner as to prevent the sun from striking the thermocouples directly as well as to provide minimum obstruction of air movement. These were mounted on lengths of twelve-gauge wire which were inserted into the soil at the desired positions. Thermocouples were also placed one inch deep in the soil directly under those one inch above the soil surface, and also in the soil which was not covered.

Readings were made manually with a potentiometer when the soil was dry, January 3 and 4, and twenty-four hours after the soil was completely wetted, January 12 and 13. Temperatures were plotted on a profile of the cover, and intervals of $1^{\circ} \mathrm{F}$. were determined by interpolation between adjacent points. Isotherms were drawn between points of equal temperature. Because of the uncertainty of the location at the periphery of the covers, the isotherms are indicated by dotted lines in the figures. In all the figures, the south (front) side of the cover is at the left and the north side is at the right. 


\section{RESULTS AND DISCUSSION}

In both seasons of the trials, temperatures were recorded throughout a twenty-four-hour period. Those recorded early in the morning during the period of minimum temperatures are, in one respect, much more important than those taken throughout the remainder of the day. Several frosts, usually of the radiation type, normally occur in the vegetable-growing areas of southern California during January and February. Warm-season crops growing at this time of year require some type of protection. The ability to protect from frost is therefore an important requirement of any structure used to cover plants during the winter.

The degree of frost protection or the increase in temperature over outside air temperature varies considerably, depending upon several factors. These include properties of the covering material, moisture condensation on the film, heat input the previous day, thermal properties of the soil, cloud cover, wind, and others. It is obvious, then, that the frost protection provided by a cover cannot be fully evaluated without taking these factors into consideration, and this would involve the collection of data over an extended period of time. Readings taken in this study involved a limited number of days; therefore, only a general indication of frost protection can be reported here.

Although an effort was made to shield the thermocouples from the direct rays of the sun, no attempt was made to intercept radiation from any other source or to prevent radiation from the thermocouple itself. It is recognized that such precautions are necessary when critical temperature measurements are taken. In this study, however, we are more interested in gross differences, and very little emphasis is placed on differences of less than $1^{\circ} \mathrm{F}$.

\section{Effect of Perforations}

It has become strikingly evident that when plastic covers are used over fieldgrown vegetables, some type of rentilation is essential shortly after emergence of the plants. It has been observed that cantaloupe plants growing under an unopened and unperforated cover soon become extremely succulent and tender. Plants in this condition are very susceptible to injury by disease, frost, and sudden exposure to wind and sun. If plants are allowed to continue growing under an unventilated cover, they become severely stunted compared with those under a perforated cover. It has also been evident that although plant growth is luxuriant under a cover with perforations as the only ventilation, eventual removal of the covers would be difficult because of the nonhardened condition of the plants. If perforations are used, it is necessary that additional ventilation be supplied within a short time after emergence to start the hardening process in preparation for complete removal of the covers.

Studies made before 1960 (Shadbolt and McCoy, 1960) had failed to show any plant response as a result of perforating the film. In 1960, however, when wide-based covers were used, there was a significant increase in plant weight at one and two months after planting as a result of perforations, shown in table 2. All covers were opened at the ground level on the south side one month after planting. The benefit of the perforations observed early in the 
season was not evident at harvest. It appears, then, that the main advantage of perforations occurs before the time the covers are opened. In fact, the use of perforations could, under some conditions, permit a slight delay in the opening of the covers. This would be desirable, as opening the covers causes considerable reduction in temperature-an aspect considered later in this report.

The presence of perforations in the films would also be expected to affect the temperature under the covers during both day and night. During the night, when heat is being radiated from the soil, the temperature would be expected to diminish slightly under the perforated film because of convection

TABLE 2

EARLY PLANT WEIGHTS AND YIELDS OF CANTALOUPES FROM SEVERAL TYPES OF COVERS USED IN $1960^{*}$

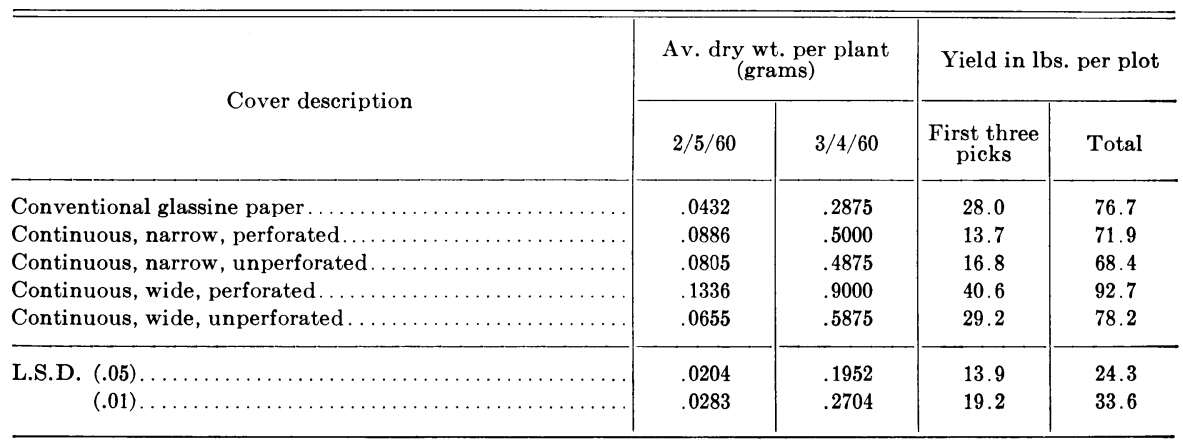

* Seed planted and covers erected January 4, 1960. All continuous covers were opened about one inch from the ground level on the south side on February 3.

of warm air upward through the perforations. During the day, because of rapid heating and expansion of the air under the covers, this convection would proceed at a much more rapid rate. In addition, winds, which more often occur during the day than during the night, would cause further movement of air through the perforations.

Minimum Temperatures. Figures 1 and 2 show the temperatures and isothermic patterns under two covers, which differ only in that the cover in figure 2 was perforated and the other was not. At the time of minimum temperatures, readings at the center and the south (left) side near the ground level were similar under both structures. The other three points showed a reduction of 1 to $1.5^{\circ} \mathrm{F}$. in temperature under the perforated cover. Under both covers, the temperature at the location of the plant was about $6.5^{\circ}$ above outside air temperature. Even though the outside temperature at this time was $7^{\circ}$ above freezing, it can be assumed that under actual frost conditions some measure of frost protection would be afforded. The presence of perforations in the film did not appear to affect greatly the frost-protection properties of the structure.

Daytime Temperatures. At the midmorning and noon readings, the main effect of perforations on the temperature was a general over-all cooling, particularly at those points near the soil level. The area of highest temperature under the unperforated cover was near the ground level at the south side. 



Fig. 1. An unperforated and unopened continuous polyethylene cover erected on a sloping bed. Air and soil temperatures were recorded February 4, 1960. Isotherms join interpolated points of equal temperature. 

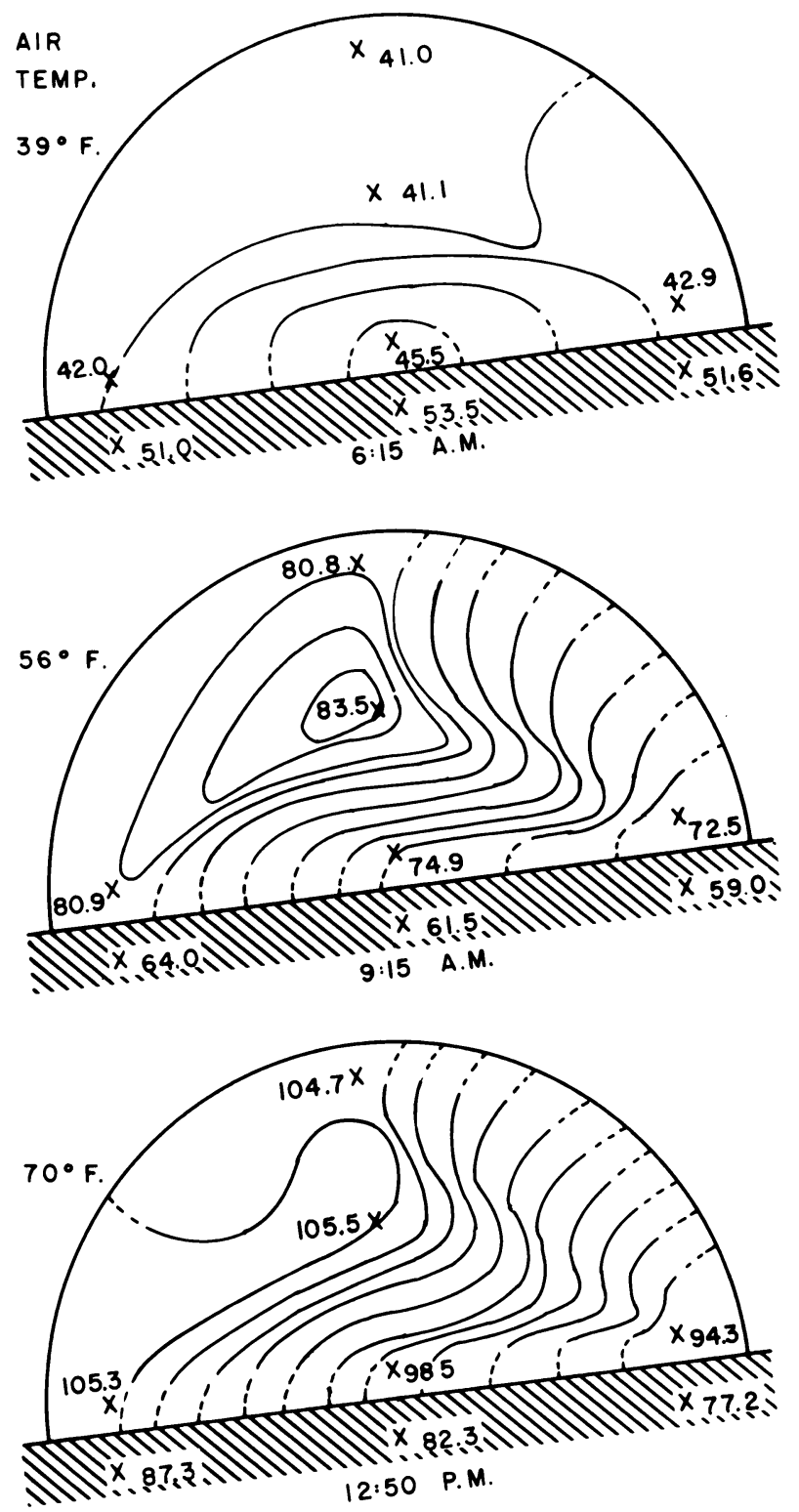

Fig. 2. A perforated and unopened continuous polyethylene cover erected on a sloping bed. Air and soil temperatures were recorded February 4, 1960. Isotherms join interpolated points of equal temperature. 

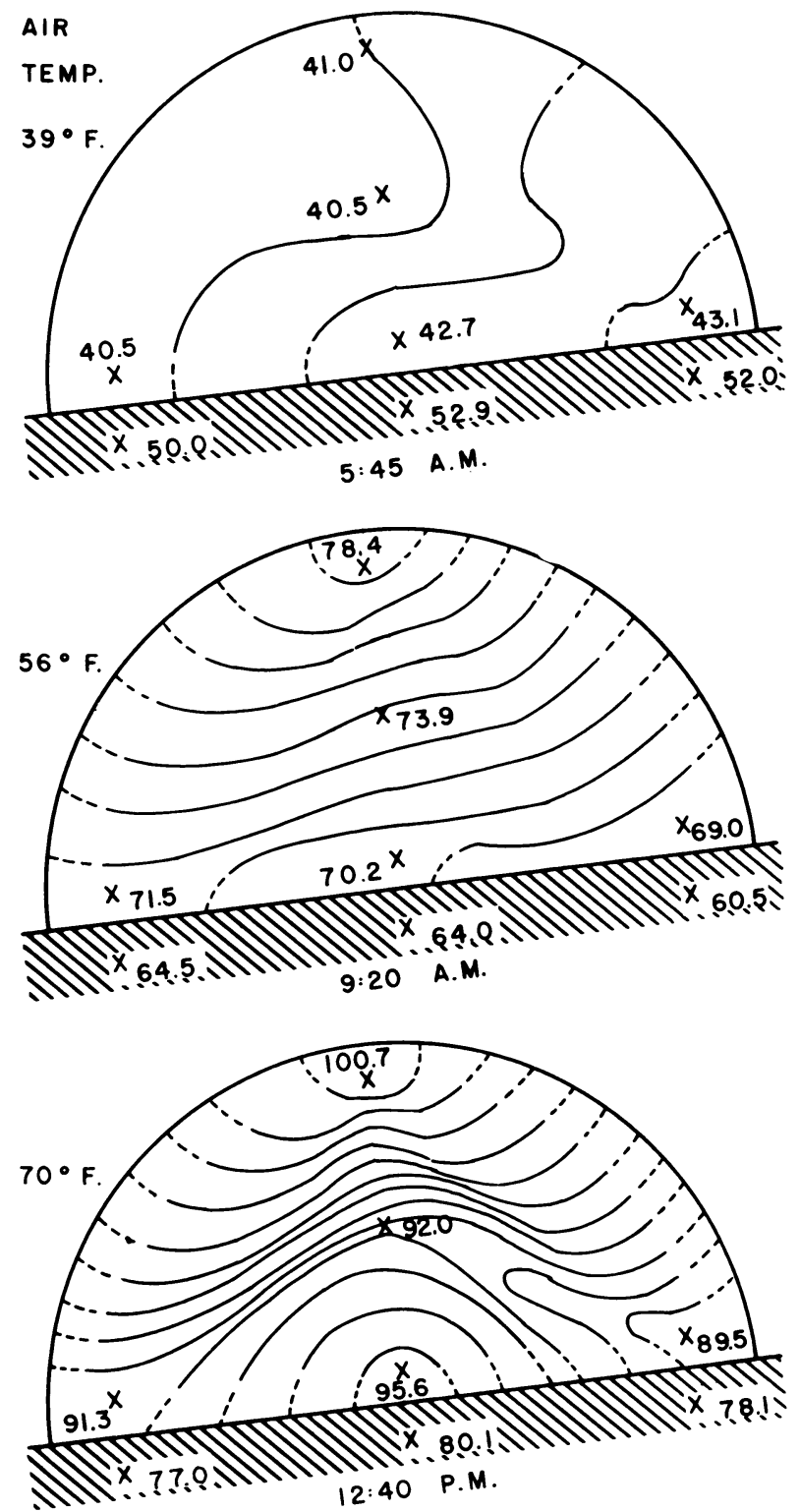

Fig. 3. An unperforated and opened continuous polyethylene cover erected on a sloping bed. Air and soil temperatures were recorded February 4, 1960. Isotherms join interpolated points of equal temperature. 
When the film was perforated, this area was shifted upward, probably reflecting the convection of heated air through the perforations. The general isothermic pattern was changed, from the unperforated cover where isotherms arose from the soil and sloped to the south side of the cover, to one where they sloped to the north side of the cover when perforations were present.

Soil temperatures under both covers were similar at the early morning readings. Later in the day, however, soil temperatures under the perforated covers were several degrees lower than under the unperforated ones. The soil temperature at the south side of the cover was higher than that at the center or the north side, except in the early morning. This trend very closely followed the trend of air temperature.

The underlying reason for the depression of growth under the unperforated covers, or its stimulation as a result of perforations, is somewhat obscure. There are several factors, however, which may tend to limit plant growth. One of the most probable of these is a deficiency of carbon dioxide during the day, brought about by high levels of photosynthesis and the relative impermeability of the cover to carbon dioxide. During 1960, gas samples were taken from under both perforated and unperforated covers containing large plants and analyzed for carbon dioxide. No evidence was found of a lack of carbon dioxide at any time of the day or night. In fact, the level did not go below .35 per cent, which is more than adequate for normal photosynthetic activity. Another possible factor which could have been involved was that of higher daytime temperatures under the unperforated covers. On the day that measurements were taken, temperatures at the center of the cover near ground level, where plants were growing, were 5 and $7^{\circ} \mathrm{F}$. higher under the unperforated cover than under the perforated one (figs. 1 and 2). It is possible that this higher temperature, when in the range of 105 to $110^{\circ} \mathrm{F}$., is sufficient to cause injury.

The effect of the size, spacing, and location of the perforations would be expected to influence the temperature and plant response. Further studies of this aspect appear to be desirable.

\section{Effect of Side Ventilation}

One of the commonest methods of ventilating continuous plastic covers is to open them at the ground level on one side. Under normal growing conditions, this opening is increased in size as the season progresses until finally the covers are removed completely. The covers used in this study were on eastwest beds which sloped to the south. The plastic on the south or leeward side was raised about one inch above the soil level.

Minimum Temperatures. The temperatures recorded in the early morning before sunrise of February 4, 1960, under an unopened and an opened cover, are shown in figures 1 and 3, respectively. Neither cover was perforated. The depression of temperature at this time of day as a result of opening the cover was much greater than was the case when the cover was perforated (fig. 2 ). Temperatures throughout the opened cover were reduced from 1 to $3^{\circ} \mathrm{F}$., compared to those of the unopened cover. The warmest area was shifted from the center of the cover in the unopened one to the north side of the cover 

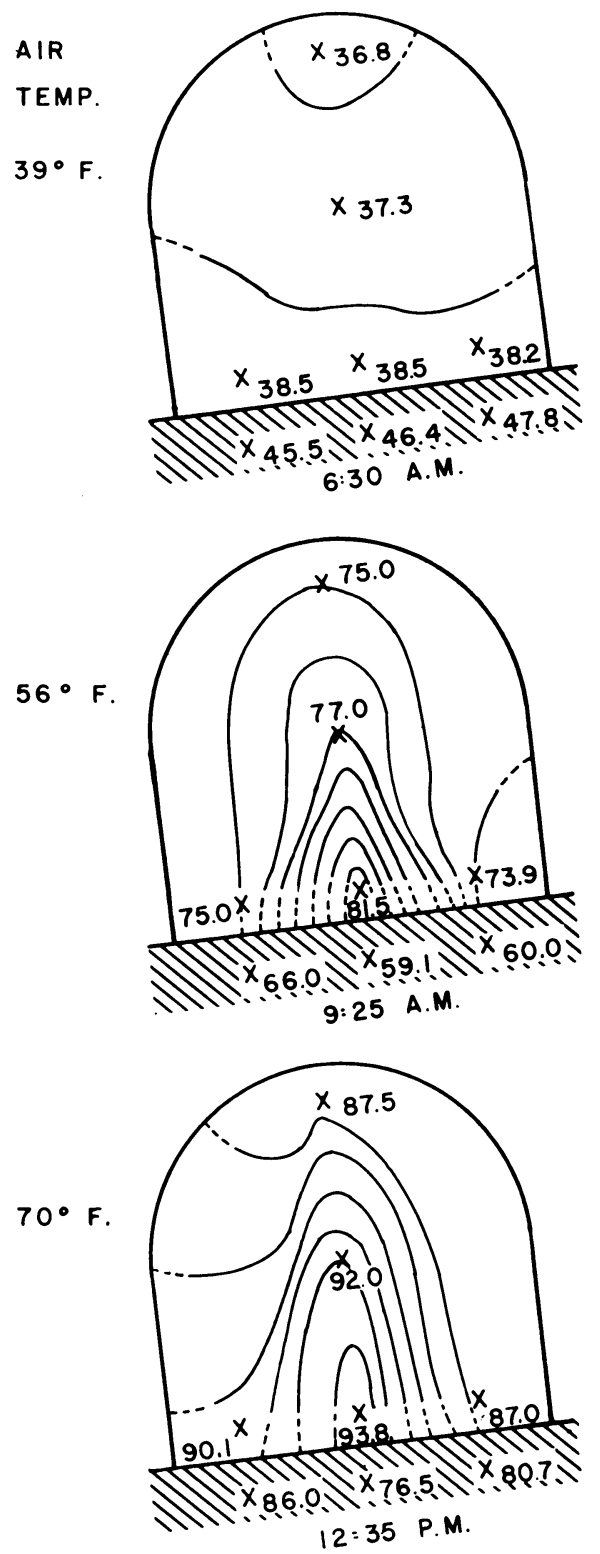

Fig. 4. A perforated and opened continuous polyethylene cover erected on a sloping bed. Air and soil temperatures were recorded February 4, 1960. Isotherms join interpolated points of equal temperature. 
when it was opened. Soil temperatures were $1^{\circ}$ lower at the south side and center of the opened cover.

Daytime Temperatures. Opening the cover at the ground level resulted in a great depression of daytime temperatures, particularly adjacent to the opening. Temperatures were 16.7 and $18.2^{\circ} \mathrm{F}$. lower than those under the unopened covers at this location at the midmorning and noon readings, respectively (figs. 1 and 3 ). The area of highest temperature shifted from near the ground level in the unopened cover to the top of the cover in the case of the opened one. Under the opened cover, the isotherms are arranged in a somewhat horizontal position, contrasted to a vertical position in the unopened cover.

\section{Effect of Cover Shape}

In 1960, the one narrow cover which was included in the study was both opened and perforated (fig. 4). A direct comparison with the wide cover is difficult because none of the wide covers were both opened and perforated. It is apparent, however, that both air and soil temperatures under the narrow cover were generally several degrees cooler than under any of the wide covers. In the early morning, the temperature at the base of the narrow cover was slightly lower than outside air temperature, indicating a lack of potential frost protection under this particular cover. It has been observed in the field on many occasions, and borne out in previous studies (Shadbolt and McCoy, 1960 ), that plant growth under a narrow cover is much slower than under a wide cover. This same response is also indicated in the data presented in table 2, where the wide perforated cover showed significantly greater early growth and early yield than did the narrow perforated cover. This trend was not so evident where unperforated covers were used.

In 1961, a study was set up specifically to determine the effect of cover shape on air and soil temperatures. Temperatures recorded during two periods are shown: for January 3 and 4, under dry soil conditions, in figure 5; and for January 12 and 13, under wet soil conditions, in figure 6 .

One of the most striking features of the air temperatures under the covers was the great difference in temperature which occurred in different locations under a cover at any one time. The greatest range which was recorded occurred under the wide-based cover, where there was a difference of $17.8^{\circ} \mathrm{F}$. between two locations under the cover at the early afternoon reading (fig. $5, \boldsymbol{A})$. Differences in temperature under any one cover at the early morning readings were slight, and ranged from 1 to $3^{\circ}$. These differences are important in that they point out the error which may be encountered by taking spot readings under the covers.

A few general comments may be made regarding the location of the warm and cool areas under the covers. In the case of the narrow-based cover, there was no consistency in the location of the warm or cool areas. Under the intermediate cover, in all cases except the early morning readings, the coolest area occurred at the periphery on the north side near the apex. The warmest location occurred on the south side. Under the wide-based cover, the coolest area occurred near the ground level on the north side, the warmest on the south side. Very little difference was observed in the isothermic patterns 

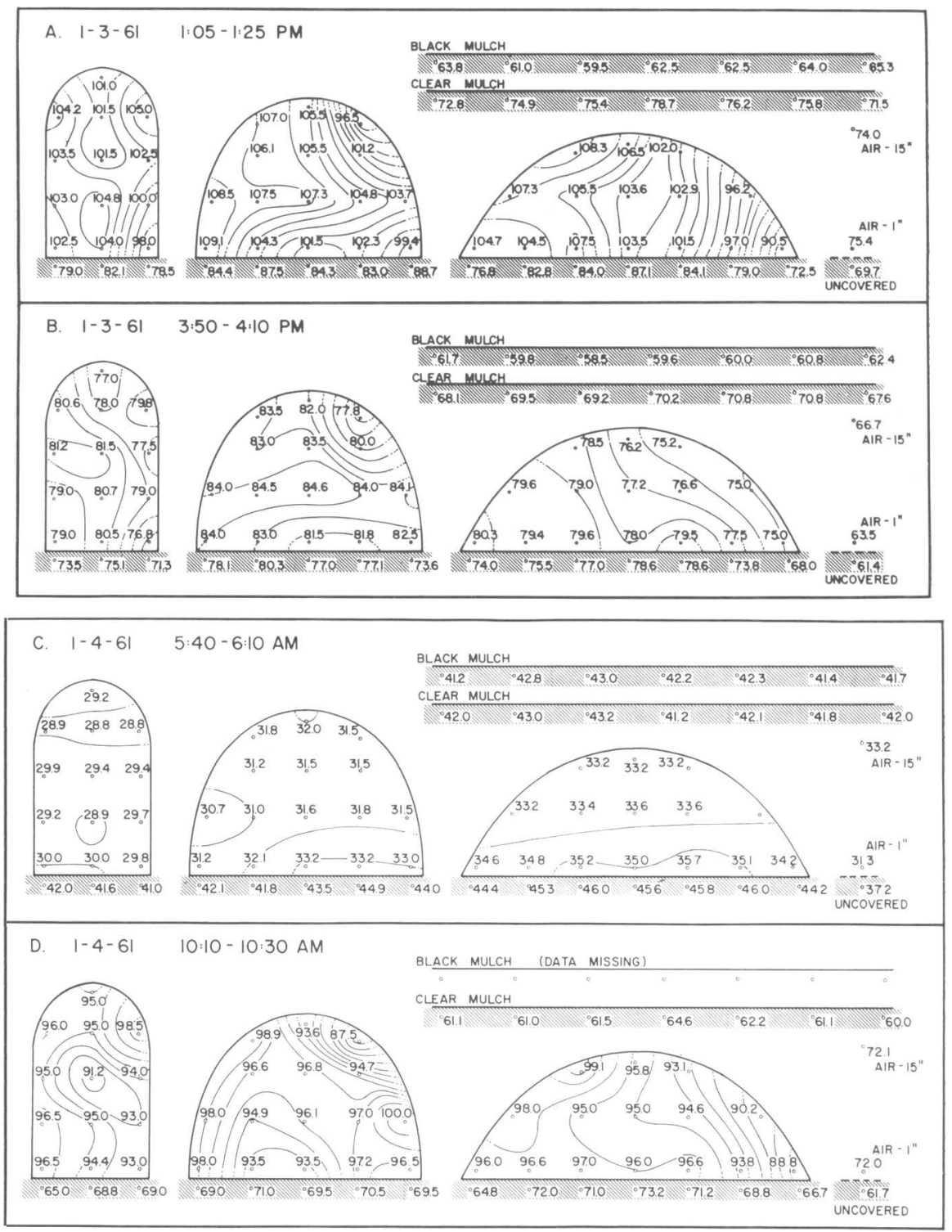

Fig. 5. Soil and air temperatures under unventilated polyethylene covers under dry soil conditions. A four-foot width of plastic was exposed above the ground in all cases, and the widths of the covers at the base were one, two, three, and four feet, the last-named being a mulch. Isotherms at intervals of $1{ }^{\circ} \mathrm{F}$. join interpolated points of equal temperature. Temperatures were measured at four times during the day: $A$, early afternoon; $B$, late afternoon ; $C$, early morning; and $D$, midmorning. 



Fig. 6. Soil and air temperatures under unventilated polyethylene covers under wet soil conditions. A four-foot width of plastic was exposed above the ground in all cases, and the widths of the covers at the base were one, two, three, and four feet, the last-named being a mulch. Isotherms at intervals of $1^{\circ} \mathrm{F}$. join interpolated points of equal temperature. Temperatures were measured at four times during the day: $A$, early afternoon; $B$, late afternoon; $C$, early morning; and $D$, midmorning. 
under any one cover at similar times of the day, whether taken under dry or wet soil conditions .

Minimum Temperatures. Comparison of covers of different widths at any one time during the day is difficult because of the diversity of the isothermic patterns, and because of the large number of readings that were taken under each cover. By comparison of air temperatures at the center of the covers near the ground level, a definite trend is indicated at only the early morning readings (figs. $5, C$, and $6, C$ ). In this case, the temperature appears to be related to the soil area covered, in that the lowest temperature was recorded under the narrow-based cover, and the highest temperature under the widebased cover. It is apparent that from the standpoint of night temperatures, the wide cover is much more desirable than the narrow one. This would be particularly significant under frost conditions. On January 4, the outside air temperature one inch above the soil surface was $31.3^{\circ} \mathrm{F}$. The temperature at the center of the wide cover one inch above the soil was $35^{\circ}$, or an increase of $3.7^{\circ}$. On January 13, a similar increase over outside air tcmperature was recorded under the wide cover, although in this case, temperatures were considerably above freezing.

It is significant that the highest temperatures recorded under the narrow covers at this early morning reading were 1.3 and $1.2^{\circ}$ lower than outside air temperatures on January 4 and 13, respectively. It seems that a cover of this shape would be detrimental from a frost-protection standpoint.

There is an apparent discrepancy in the data of 1960 and 1961. In 1960 and in earlier years (Shadbolt and McCoy, 1960), early morning temperatures under the wide covers showed a considerably greater increase over outside air temperatures than that which occurred in 1961. The only explanation which can be offered for this effect is that before 1961, the covers were erected on sloping beds. No direct comparisons have been made of covers on flat and sloping beds; however, other studies have shown that there is considerable increase in daytime soil temperatures on a sloping bed compared with those on a flat bed. It is believed that this increased heat reservoir in the soil may place a cover on a sloping bed at considerable advantage.

Daytime Temperatures. During the daytime, the relationship of temperature to the size of the cover was not so consistent as was the case during the minimum temperatures. Whether the average of the two thermocouple locations near the ground level at the center of the cover, or the average of six locations in this area, or the average of all the locations under each cover was used, the temperature under the two-foot cover was consistently higher than that under the one-foot cover. The average temperature under the three-foot cover was also consistently lower than under the two-foot cover. These trends occurred whether temperatures were taken under dry or wet soil conditions, and were most pronounced at the noon and afternoon readings. These data would suggest that daytime temperatures are more closely related to the volume of air enclosed by the cover than to the soil area covered, as occurred during minimum temperatures.

Differences in soil temperatures between different covers and mulches were much more sharply defined than those of the air temperatures. Several consistent and outstanding differences can be pointed out. In ncarly every case, 
the soil at the edge of the cover was somewhat cooler than that near the center, regardless of the time of day.

The warmest soil temperature recorded under each of the raised covers was plotted at intervals through a twenty-four-hour period under both dry and wet soil conditions (fig. 7 ). The soil temperatures under the three covers were, at all times of the day, several degrees warmer than those of the open soil. At

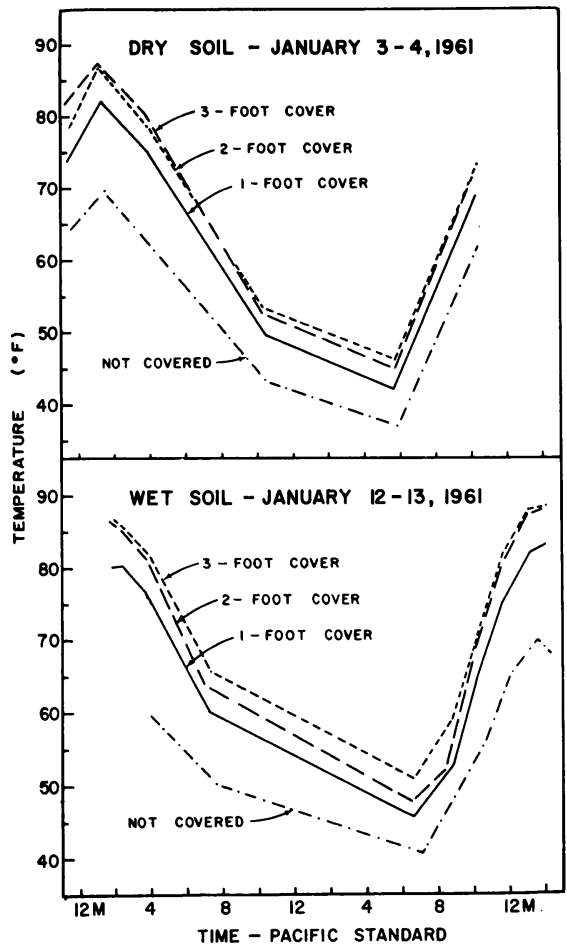

Fig. 7. Soil temperatures at the one-inch depth under raised plastic covers of three widths, and in open, uncovered soil under dry soil conditions, January 3 and 4, 1961, and under wet soil conditions, January 12 and 13.

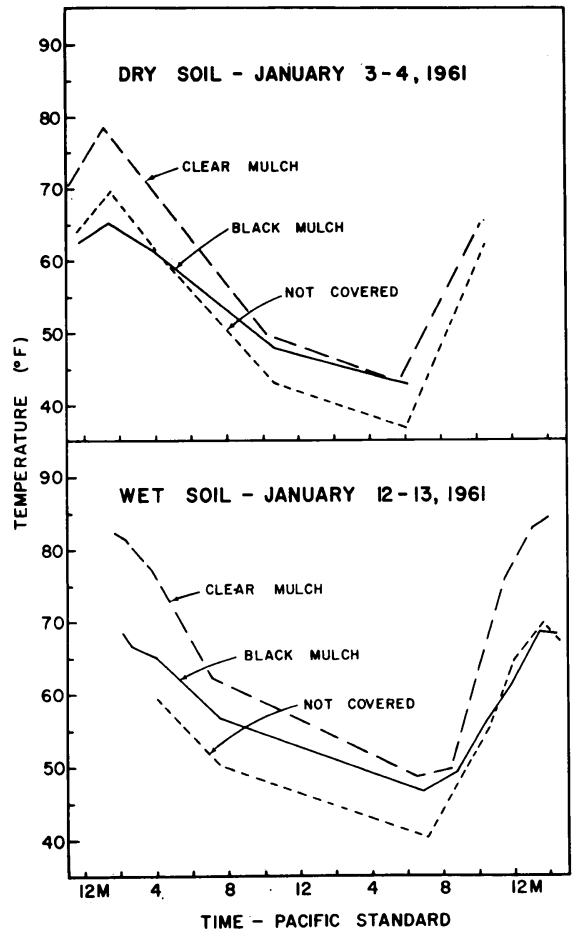

Fig. 8. Soil temperatures at the one-inch depth under clear and black plastic mulch, and in open, uncovered soil under dry soil conditions, January 3 and 4, 1961, and under wet soil conditions, January 12 and 13.

both dates, soil under the narrow one-foot cover was several degrees cooler than that under either of the wider covers. Under dry soil conditions on January 3, soil temperatures under the two-foot and three-foot covers were very similar. When the soil was wet, however, soil under the three-foot cover was consistently warmer than that under the two-foot cover.

The soil temperatures under the clear and the black mulches showed some pronounced differences. The soil temperatures one inch deep under both dry and wet soil conditions throughout a twenty-four-hour period are shown graphically in figure 8. Soil temperatures under the clear mulch were consistently higher than those of the uncovered soil. Temperatures under the black mulch were approximately $12^{\circ} \mathrm{F}$. lower than those under clear mulch 
during midday, but they were nearly comparable at their minimum. Temperatures in open soil were higher than those under black mulch for a relatively short period during midday. In other words, uncovered soil warmed faster and reached a higher maximum temperature, but also cooled faster than soil covered by black mulch.

\section{SUMMARY}

Soil and air temperature patterns were studied under several types of polyethylene mulches and raised continuous covers. The results of these studies may be summarized as follows:

1. There were large differences in daytime air temperatures at any one time under the raised covers, depending on the location under the cover. The greatest range recorded was $17.8^{\circ} \mathrm{F}$.

2. Soil temperatures under the covers and mulches were, in general, highest near the centers of the covers and lowest near the edges.

3. Greater early plant growth occurred when covers were perforated than when they were not. Perforations in the film had very little effect on the minimum air and soil temperatures under the covers. Daytime temperatures were generally reduced, particularly near the ground level, when perforations were present.

4. Minimum night air temperatures were reduced from 1 to $3^{\circ} \mathrm{F}$. as a result of lifting one side of the cover about one inch from the soil surface. Air temperatures during the day were reduced by as much as $18^{\circ} \mathrm{F}$. adjacent to the opening.

5 . At the time of the minimum, the air and soil temperatures were somewhat proportional to the width of the covers. The wide-based cover was warmest; the narrow-based one was coolest. Thus, the wide-based cover was more favorable with regard to potential frost protection.

6. Soil temperatures under clear mulch were as much as $12^{\circ} \mathrm{F}$. higher during the day than under black mulch. Minimum temperatures were nearly comparable. Minimum temperatures under both mulches were 6 to $7^{\circ} \mathrm{F}$. warmer than in uncovered soil.

\section{LITERATURE CITED}

Clarkson, V. A.

1960. Effect of black polyethylene mulch on soil and microclimate temperature and nitrate level. Agron. Jour. 52:307-9.

Honma, Shigemi, Frank McArdee, John Carew, and D. H. Dewey

1959. Soil and air temperature as affected by polyethylene film mulches. Mich. Agr. Expt. Sta. Quart. Bul. 41:834-42.

Shadbolt, C. A., and O. D. McCoy

1960. Temperature and plant responses to paper and plastic protectors on cantaloupes. Hilgardia $30(9): 247-66$.

VOTH, VICTOR, and R. S. BRINGHURST

1959. Polyethylene over strawberries. Calif. Agr. 13(5):3, 14.

Waggoner, Paul E., Patrick M. Miller, and Henry C. De Roo

1960. Plastic mulching: principles and benefits. Conn. Agr. Expt. Sta. Bul. 634. 
The journal Hilgardia is published at irregular intervals, in volumes of about 600 pages. The number of issues per volume varies.

Subscriptions are not sold. The periodical is sent as published only to libraries, or to institutions in foreign countries having publications to offer in exchange.

You may obtain a single copy of any issue free, as long as the supply lasts; please request by volume and issue number from:
Agricultural Publications
Room 207 University Hall
2200 University Avenue
Berkeley 4, California

The limit to nonresidents of California is 10 separate issues on a single order. A list of the issues still available will be sent on request.

In order that the information in our publications may be more intelligible it is sometimes necessary to use trade names of products or equipment rather than complicated descriptive or chemical identifications. In so doing it is unavoidable in some cases that similar products which are on the market under other trade names may not be cited. No endorsement of named products is intended nor is criticism implied of similar products which are not mentioned. 